\title{
Knowledge-based Decision Support System (KBDSS) for Science \& Medical of Chinese Olympic Teams
}

\author{
Hao $\mathrm{Wu}$ \\ Chief Scientist of Chinese National Rowing Team \\ Capital Institute of Physical Education and Sports, \\ 100191, Bei Jing, CHINA \\ wuhao@cupes.edu.cn
}

\author{
Jianbing Li (Corresponding author) \\ Capital Institute of Physical Education and Sports, \\ 100191, Bei Jing, CHINA \\ Lijianbing@cupes.edu.cn
}

\begin{abstract}
The Chinese Olympic Teams were very successful in 2008 Beijing and 2012 London Olympic Games. These results were under efforts of the Knowledge-based Decision Support System (KBDSS) for Science \& Medical of Chinese Olympic Teams, including Sports Expert System, Case-based Decision Support System (CBDSS), Relationship Management System, Fundamental Strategies and Innovation System etc. this research investigated historical evolution of science \& medical support system for Chinese Olympic Teams, revealed an organizational structure and practical function of KBDSS for Science \& Medical of Chinese Olympic Teams. Also studied related policies and organism for backup system of national teams.
\end{abstract}

Keywords- Knowledge-based Decision Support System (KBDSS); Chinese Olympic Teams; Olympic Games

\section{INTRODUCTION}

The Chinese Olympic Teams got 51 golden Medals and 100 medals in 2008 Beijing Olympic Games. As a so called "Hi-Tech Olympics", what is the behind-the-screen power of The Chinese Olympic Teams, and what is the Science \& medical system supporting these historical achievements of Chinese Olympic sports? How about the Knowledge-based Decision Support System (KBDSS) was developed? [3] Is there any interesting cases and stories that happened from it? The report would give you some profound understanding and brand new views of what are the highlights of KBDSS for Science \& Medical of Chinese Olympic Teams [1] [2]

\section{HISTORICAL EVOLUTION OF SCIENCE \& MEDICAL SUPPORT FOR CHINESE OLYMPIC TEAMS}

As we know, the former Soviet Union brought the first scientific sports medicine concepts and system to China in the 1950s.goverment support the needs of athletes till 1980s.

After the 1980s, China turned to Europe and the US for the latest sports technical and scientific breakthroughs, using concepts from both Soviet Union and United States. For example, once we try to explain some phenomena of "sports fatigue", Chinese sports scientists prefer to use both "Supercompensation" concept which was from Soviet Union, and "Stress" concept which was from United States, and then we start to build our own concept for training science after 1984 Los Angeles Olympic Games. At that moment is the first time that new Republic China came back to Olympic Games.
In the 1990s, just before 1996 Atlanta Olympic Games especially, we choose the third resource of concepts, using traditional Chinese medicine system which is built for more than 5000 years.

In new millennium, Chinese Olympic Teams started to establish a modern Science \& medical support system, because Beijing had gotten host right of 2008 Olympic Games. Central Government, local provincial Governments and main people, almost including all society members showed a strong request that national teams "must" set a new golden medals record in 2008 Olympic Games.

Beijing Olympics was most-watched and was medal most-wanted in history.

As we know, a record 4.4 billion people, or about twothirds of the world's population, watched the Beijing Olympic events. On one hand, this has made the Chinese society put more pressure to national teams. Each national team had to be stronger than ever, and tried to do the best to get medals, on the other hand, very tough doping control policy means all teams only can think of improving performance by scientific training, and depended on a updated science \& medical support system. Any Chinese sports achievements would be witnessed right in home, Beijing.

\section{A VIEW OF SCIENCE \& MEDICAL SUPPORT SYSTEM OF CHINESE OLYMPIC TEAMS}

Fundamental strategies of establishing an operable 、 feasible and effective support system[4]

Attaching great importance to innovation and development and possessing a state-level technology have guaranteed athletes could get significant improvement without injuries.Systems are with an unbalanced development in different Chinese national teams injury

Case Analysis: the 110m hurdles athlete----Liu Xiang's

A top Chinese athletic hero Liu Xiang' s injury to his right Achilles' tendon forced him out of Olympic 110 meters hurdles.

He is only 25 years old. He has even got unhealed injury for 6 years! But liu's coach never let public people and media know this point. This coach always believed his training was right, no need any suggestion from medical experts, his daily training schedules for Liu are brilliant and keep the champion free from injury. Head coach of the 
Chinese national track and field team, said, "Liu Xiang's coach was not listening to any suggestion from experts of Nutrition and Sports Medicine, just believed that food is everything of nutrition." Liu and his coach went to US and got operation on Dec. 5, 2008. They will pay more attention on athlete's medical and nutrition support during the daily training of 2012.

\section{Sports Science Support System}

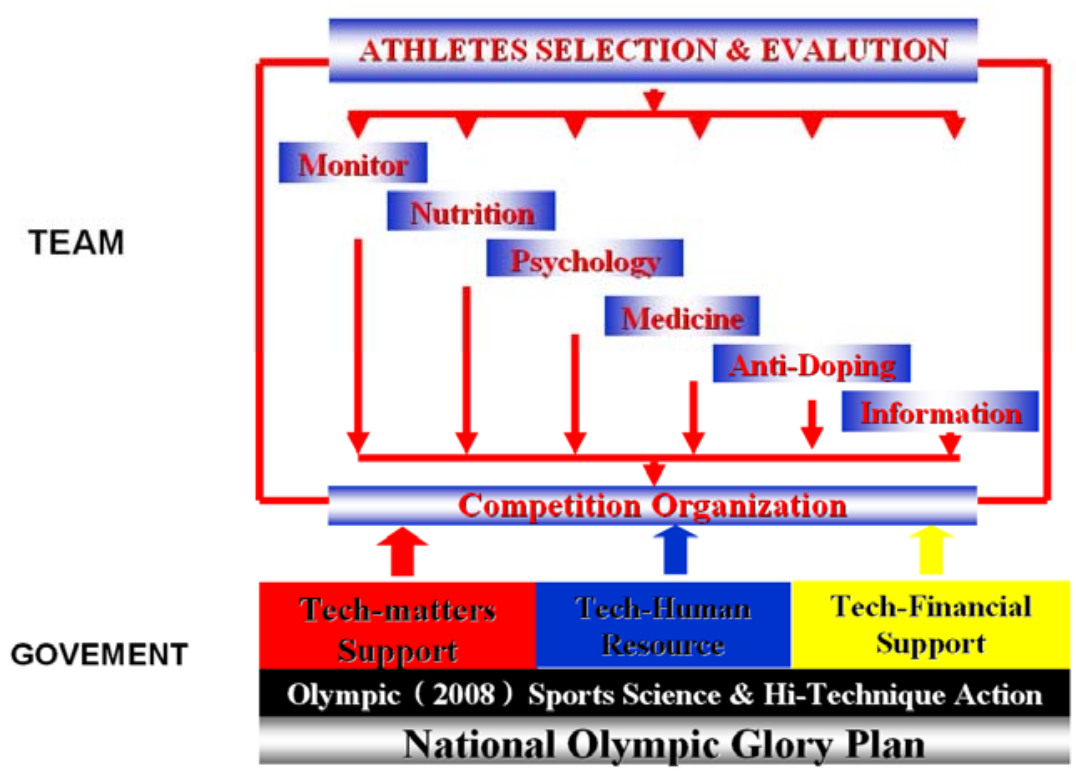

Figure 1. General Strategy Models of support system of Chinese Olympic teams

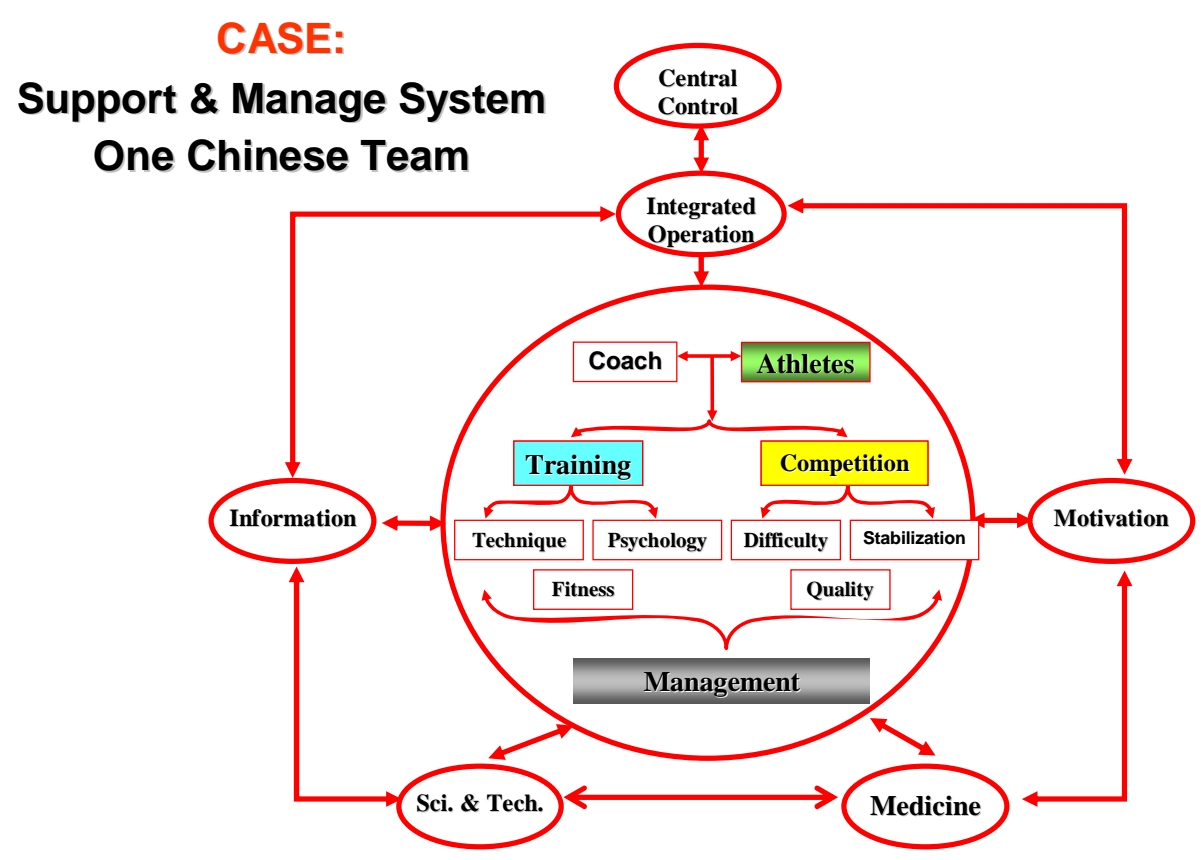

Figure 2. Case Analysis: Organizational structure model of support system of one Chinese Olympic team 


\section{HighligHTS OF SCIENCE \& MEDICAL SUPPORT FOR} CHINESE OLYMPIC TEAMS IN 2008 OLYMPIC GAMES

New government Policies and Organism for backup National team.

Set up 36 research \& medical backup Groups for 36 Olympic teams, group members were from international wide. We combined strengths from different sources and integrate the supporting resources. Backup group watched athletes every day. They help them effective training, even warm up for training and afterwards help their recovery, also with biochemical 、 physiological and biomechanical evaluations, analyzing and feedback.

For those athletes who do get sick or hurt, has boosted staff at central sports hospital from 100 to 150 in preparation for the Olympics and half of them is doctors trained in sports medicine, some got professional medical training in the US. Along with other medical staff from the hospital they will be playing a bigger part in Olympic preparations from beginning. Injuries prevention is always the big thing for medical backup team. Even modern sports medicine came late to China and for many years the nation has been playing catch-up with world leaders such as the US and Europe countries. Experts from the US and other countries visit Chinese Sports hospital every year. Team science \& Medical groups were accelerating the cooperation with leading foreign and domestic labs to upgrade its functions. All these will give establishes a professional team backup groups, could facing different treatment problems. Each group consisting of nearly 20 professional and assertive sports science and medical experts have won the respect and trust from our coaches and athletes.

We always emphasize that the needs from team are most important and meet the training needs is key to establishing effective support system.

Green medical treatment channels for Olympic athletes:. Olympic athletes enter professor treatment rooms every day at the one-of-a-kind hospital built inside the vast training complex in southeastern Beijing, which is the base for more than 600 Chinese athletes preparing for Olympic Games , called Beijing Sports Medicine Hospital, which is supported by Chinese Olympic Committee. Many more undergo testing and examinations at the hospital where China's top sports medicine experts are available with state-of-the-art equipment at their disposal. Athletes at this level who are training over long periods of time, especially in the run up to the Olympics, are going to have medical problems. We have to cure the problem then help recovery as faster as possible. [5] [6]

Modern High-tech Supported training of Olympic Teams

Preparing the Olympics in 2008 requires quite a bit of modern science and technology. The success of a High-tech Olympics depends on both hardware and software. We take a look at some applications of science and technology for the Beijing Olympics preparation in some National Teams.

Case: Rowing Technique Assessment etc.

Tradition medicine concept and treatment technique supported Olympic teams[7]
How we got remarkable advantages with Chinese 5000 years traditional medicine. All Olympic teams supported Chinese traditional medicine and herbal remedies. These remedies have been handed down a thousand years and this is part of our backup strength.

Case: altitude training

Anti-Doping, $100 \%$ guaranteed by science \& medical support system

Efficient Management of doping control.

Case: Anti-Doping agreement, "One to One Action"

Motivation encourage \& education Plan : personal success and nation success

Motivation changes by promoting education by leaders and a man of mark.

Medical Support System during Olympic Games Period

The Beijing Municipal Health Bureau on the Olympic medical support system

The Beijing Municipal Health Bureau (BMHB)

The Medical Support Group of BOCOG

Disease Prevention and Control Division

The Beijing Municipal Health Inspection Institute

Protecting athletes from serious infectious diseases during the Olympic Games. Additionally this vast, multilayered emergency system seeks to ensure that every patient receive timely, effective first aid and medical services. [8]

Staffing for the enormity of the Olympic Games, Beijing municipality has in place the following medical services:

- 24 disease prevention and control institutions;

- 22 sanitary supervision institutions;

- An fully equipped emergency team of 626 disease control staff, and

- 40 emergency squads consisting of 200 sanitary supervision staff

Specifically for the Games of the XXIX Olympiad there will be:

- 165 first-aid stations;

- 1,794 medical workers;

- 385 ambulances, and

- 803 first-aid personnel have been dispatched to all Olympic competition, non-competition and training venues.

In total, there will be more than 3,223 medical workers serving the Beijing Olympics.

Facing 2012 London Olympic Games

To Continue or reform?

\section{ACKNOWLEDGMENT}

The contribution of leaders, athletes and coaches in Chinese national teams.

\section{REFERENCES}

[1] Zhang J, Ouyang ZY, Miao H, Wang XK, Ren YF, Song WZ. "Characteristic comparative study of particulate matters in Beijing before and during the Olympics”. Huan Jing Ke Xue. 2013 Jul;34(7): pp. 2512-8

[2] Gao Y, Zhang M., "Sensitivity analysis of surface ozone to emission controls in Beijing and its neighboring area during the 2008 Olympic Games. ” J Environ Sci (China). 2012;24(1): pp. 50-61 
[3] Katayama K, Yamaguchi R, Imoto S, Watanabe K, Miyano S."Analysis of questionnaire for traditional medicine and development of decision support system. ”Evid Based Complement Alternat Med. 2014;

[4] Ferrada X, Serpell A, Skibniewski M."Selection of construction methods: a knowledge-based approach.” ScientificWorldJournal. 2013 Dec 24; pp.201

[5] Li M, Ratnanather JT, Miller MI, Mori S."Knowledge-based automated reconstruction of human brain white matter tracts using a path-finding approach with dynamic programming.” Neuroimage. 2014 Mar;88: pp.271-81
[6] Yu H, Chen X, Zhu W, Cao C."A quasi-experimental study of Chinese top-level speed skaters' training load: threshold versus polarized model.” Int J Sports Physiol Perform. 2012 Jun;7(2): pp.103-12.

[7] Kim J, Kang SK, Jung HS, Chun YS, Trilk J, Jung SH."Dietary supplementation patterns of Korean olympic athletes participating in the Beijing 2008 Summer Olympic Games.’Int J Sport Nutr Exerc Metab. 2011 Apr;21(2): pp.166-7

[8] Moy GG, Han F, Chen J."Ensuring and promoting food safety during the 2008 Beijing Olympics.” Foodborne Pathog Dis. 2010 Aug;7(8): pp.981-3 